RESEARCH ARTICLE

\title{
Correlation of Parotid Gland Function in Head and Neck Cancer Patients treated with Intensity-modulated Radiotherapy
}

\author{
Sukhjinder Kaur Khosa, Sonal Vahanwala, Sandeep S Pagare
}

\begin{abstract}
Xerostomia is one of the most common side effects after radiation therapy for treating head and neck cancers. Our objective was to evaluate the salivary flow in patients treated with Intensity-modulated radiotherapy with two samples: (a) Resting saliva and (b) stimulated saliva. We performed three salivary sample collections: At the beginning, during and immediately after radiotherapy. The results showed that there was a significant decrease in the whole resting (11.46\%) and stimulated (15.06\%) salivary flow values during the first 3 weeks of the radiotherapy ( $p=0.0025, p=0.0034$ respectively).
\end{abstract}

Keywords: Intensity-modulated radiotherapy (IMRT), Saliva, Parotid gland, Saliva production.

How to cite this article: Khosa SK, Vahanwala S, Pagare SS. Correlation of Parotid Gland Function in Head and Neck Cancer Patients treated with Intensity-modulated Radiotherapy. Int J Head and Neck Surg 2012;3(1):1-4.

Source of support: Nil

Conflict of interest: None declared

\section{INTRODUCTION}

Radiation therapy is a principal modality in the treatment of head and neck cancer. Its capabilities have steadily progressed with the increase in clinical knowledge and technological development.

In radiotherapy, the single most important factor is the normal tissue radiation tolerance, and the objective of optimal radiotherapy is to keep the dose to surrounding structures below tolerance. ${ }^{1}$ Although radiotherapy is effective in head and neck tumors, side effects are undesirable and may aggravate the patient's health status. ${ }^{2}$

In salivary glands, atrophy and acinar degeneration caused by radiotherapy commonly result in a decreased saliva production which is a frequent complication of head and neck irradiated patients. ${ }^{3,4}$

This complication may range from reduced salivation causing complaint of dryness of mouth to a severe form of total absence of saliva causing oral mucositis.

\section{INTENSITY-MODULATED RADIATION THERAPY}

Over the last 10 years, there has been an explosion in the development and implementation of an advanced form of radiotherapy called Intensity-modulated radiation therapy
(IMRT). This represents a major shift in the practice of modern radiotherapy. ${ }^{5}$
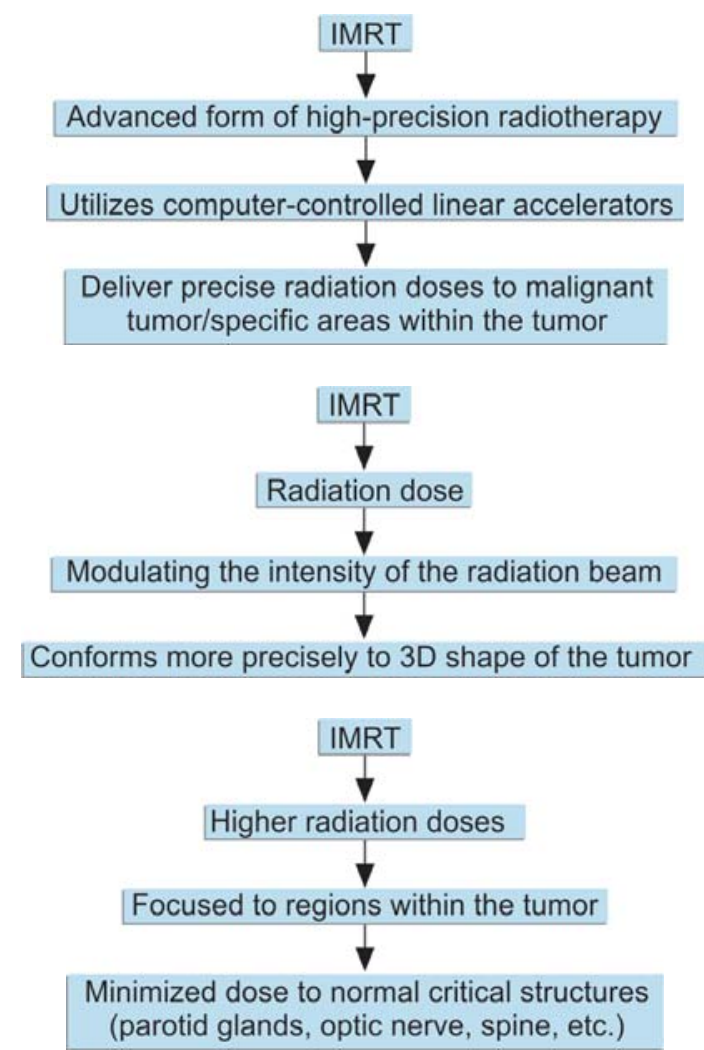

\section{AIMS AND OBJECTIVES}

1. To evaluate changes in quantity of saliva in patients with head and neck cancer treated with IMRT.

2. To measure the quantity of whole resting saliva (WRS) and

3. To measure the quantity of whole stimulated saliva (WSS):

a. Before the commencement of IMRT

b. After 3 weeks and

c. After the completion of IMRT, i.e. 6 weeks.

\section{MATERIALS AND METHODS}

This study was conducted in collaboration with IMRT, Bhalabhai, Nanavati Hospital, Mumbai. A total of 15 patients with diagnosed head and neck cancer were selected, 
who planned to undergo and treated with IMRT from April 2011 to July 2011.

\begin{tabular}{|c|c|}
\hline Inclusion criteria & Exclusion criteria \\
\hline - 18 years of age & $\begin{array}{l}\text { - Previous history of radiotherapy } \\
\text { or surgery }\end{array}$ \\
\hline $\begin{array}{l}\text { - Diagnosed head and } \\
\text { neck cancer }\end{array}$ & $\begin{array}{l}\text { History of any other } \\
\text { malignancies or diseases of } \\
\text { salivary glands }\end{array}$ \\
\hline $\begin{array}{l}\text { - Histologically } \\
\text { confirmed } \\
\text { carcinomas }\end{array}$ & $\begin{array}{l}\text { - Concomitant chemotherapy } \\
\text { - Medications that can } \\
\text { affect salivary gland function } \\
\text { - Antidepressants, anti- } \\
\text { histamines with anti- } \\
\text { cholinergic effects, beta } \\
\text { blockers } \\
\text { - Evidence of distant metastatic } \\
\text { disease }\end{array}$ \\
\hline
\end{tabular}

A total of 15 patients received $6 \mathrm{MV}$ parotid sparing, inverse planned IMRT (ELEKTA). IMRT planning was performed by computer optimization. The gross tumor volume (GTV) included the primary tumor and abnormal lymph nodes. The clinical target volume (CTV) encompassed $1 \mathrm{~cm}$ margin around GTV and certain at-risk anatomic sites.

A detailed case history and study chart were taken for each patient. Of these 12 were males and three were females. Written informed consent was obtained from each patient in this study.

\begin{tabular}{lc}
\hline Carcinoma of & No. of patients \\
\hline Tongue & 04 \\
Buccal mucosa & 03 \\
Alveolus & 03 \\
Vocal cord & 02 \\
Maxilla & 01 \\
Pyriform fossa & 01 \\
Nasal septum & 01 \\
\hline
\end{tabular}

\begin{tabular}{lc}
\hline Stage & No. of patients \\
\hline Stage I & 03 \\
Stage II & 06 \\
Stage III & 03 \\
Stage IVA & 03 \\
\hline
\end{tabular}

Note: Staging of cancer given by American Joint Committee (AJC)

\section{SALIVARY GLAND FUNCTION TEST}

The saliva was collected by a simple, reproducible and lowcost technique. The Saxon test is a simple, reproducible and low-cost technique to measure saliva production, which is included in the diagnostic criteria for Sjögren's syndrome. ${ }^{6}$ All salivary collections were performed under standardized conditions (Dawes, 1987) with the patient sitting comfortably in an upright position. Patients were refrained from eating or smoking 30 minutes prior to the test.

\section{METHODOLOGY}

1. Saliva was collected by swab method according to the following procedure: Patient was asked to chew on an absorbent sterile cotton gauze measuring approximately $5 \times 5 \mathrm{~cm}$ without swallowing for 3 minutes.

2. The sterile gauze that absorbed saliva was weighed and termed whole resting (unstimulated) saliva (WRS).

3. Subsequently, patients were instructed to chew a tablet of vitamin C (200 mg) for 5 minutes to stimulate secretion of saliva.

4. The weight of saliva secreted in 3 minutes was then determined.

5. The same procedure was repeated and saliva weighed was termed Whole Stimulated Saliva (WSS).

Salivary gland function was defined by as follows:

a. The weight of saliva secreted in 3 minutes at rest and

b. Weight of saliva secreted in 3 minutes with vitamin $\mathrm{C}$ stimulation for 5 minutes.

These values were collected at three intervals viz before the commencement of the IMRT, at three weeks interval and at the completion of IMRT.

The whole resting and stimulated saliva were converted to flow rates $(\mathrm{ml} / \mathrm{min})$ and these were recorded by assuming a specific gravity of 1.0 .

\section{STATISTICAL ANALYSIS}

Saliva production and the salivary flow values before, during and after three weeks of IMRT, were compared with the paired t-test. Statistical analyses were carried out using Minitab software version 11.1. Values of $\mathrm{p}<0.05$ were considered to denote significant differences.

\section{RESULTS}

The most obvious decline occurred during the first 3 weeks of radiotherapy, followed by a period of greater decline in the saliva production values.

It was noted that the saliva production decreased from:
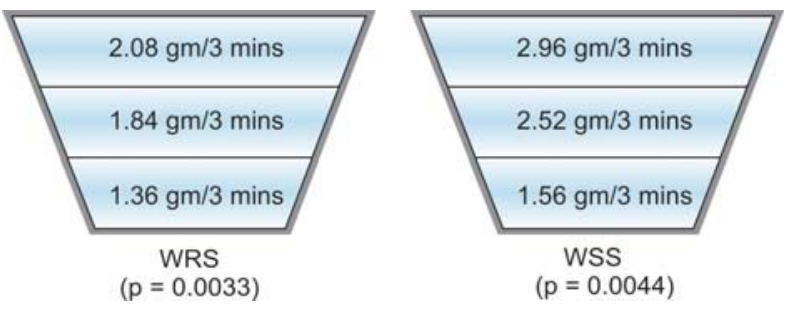
i.e. resting salivary flow rate declined from $0.69 \mathrm{ml} / \mathrm{min}$ to $0.45 \mathrm{ml} / \mathrm{min}$ in 6 weeks (34.7\%), and that of stimulated saliva flow rate, the values declined from $0.98 \mathrm{ml} / \mathrm{min}$ to $0.52 \mathrm{ml} / \mathrm{min}$ (47\%) (Figs 1 and 2).

The means and standard deviation (+ SD) for stimulated and nonstimulated saliva collected pre- and postradiotherapy are shown in table below.

\begin{tabular}{llll}
\hline $\begin{array}{l}\text { Whole resting } \\
\text { saliva }\end{array}$ & Mean (\%) & $\begin{array}{l}\text { Standard } \\
\text { deviation }\end{array}$ & p-value* \\
\hline 3rd week & 11.463 & 2.857 & 0.0025 \\
6th week & 25.647 & 2.773 & 0.0032 \\
0th-6th weeks & 34.227 & 1.481 & 0.0033 \\
\hline *paired t-test & & & \\
\hline Whole & Mean (\%) & Standard & p-value* \\
stimulated & & deviation & \\
saliva & & & \\
\hline 3rd week & 15.067 & 3.820 & 0.0034 \\
6th week & 37.67 & 4.01 & 0.0028 \\
0th-6th weeks & 47.184 & 1.893 & 0.0044 \\
\hline
\end{tabular}

*paired t-test

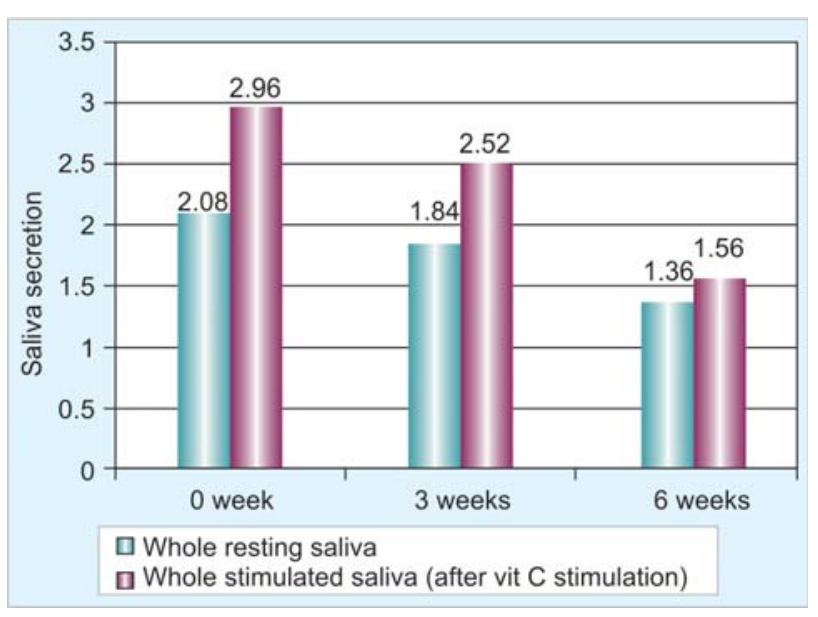

Fig. 1: Changes (gm) in saliva production in 6 weeks

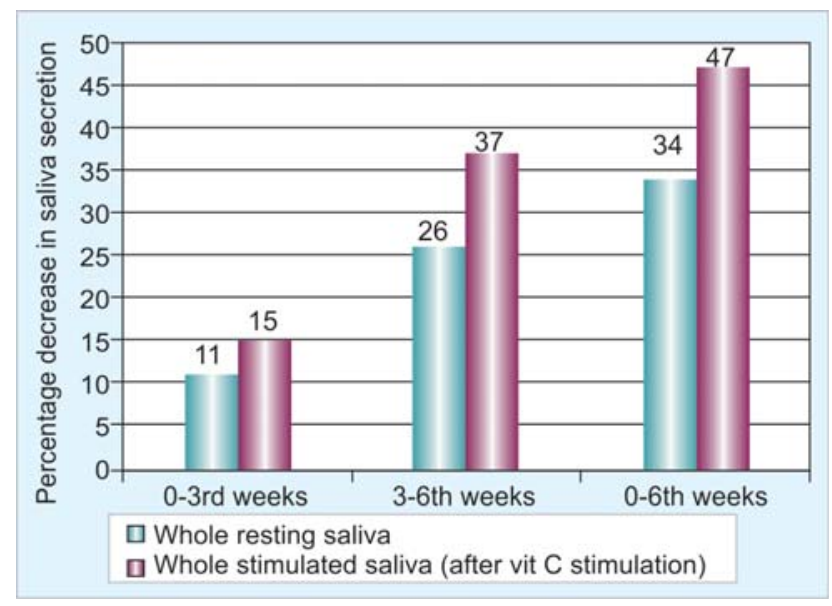

Fig. 2: Changes (\%) in saliva production in 6 weeks

\section{DISCUSSION}

IMRT is now known to preserve the parotid glands and to diminish the incidence of xerostomia. However, the IMRT results show that xerostomia could develop to some degree following IMRT, and that the salivary function may show recovery at 12 months after IMRT. ${ }^{7,8}$

Schubert and Izutsu (1987) noted that although salivary gland recovery from irradiation can be variable, and is time, dose and possibly age-dependent, maximum recovery usually occurs in the first several months postradiotherapy and may be protracted over a period of 6 to 12 months after treatment.

No study is perfect: Although our limited data upto 6 weeks of IMRT indicate no apparent recovery in salivary flow rates post-IMRT, additional observations for a longer time period would be required for definitive conclusions.

Limitations of the study: The Saxon test, a simple, low-cost technique, can objectively measure saliva production. However, some patients, especially older ones, may find it difficult to chew a gauze pad for 3 minutes. Interpretation was further complicated by the observation that most patients had taken one or more drugs (pain and nausea control) which could have reduced saliva output intermittently during radiotherapy. It was not possible to estimate the magnitude of the drug effect on salivary flow in this study.

IMRT differs from other forms of radiotherapy in a number of important areas, most critically, including localization of targets and normal tissues. IMRT has the largest potential to benefit patients where the target volume surrounds or partially surrounds an organ at risk of radiation injury. ${ }^{9}$ For example, parotid gland sparing in head and neck cancer patients.

The fact that IMRT reduces the dose to the parotid glands and that a dose-response relationship exists, that predicts a reduction in xerostomia complications, has led to widespread use of IMRT to spare the parotid glands.

\section{CONCLUSION}

Hence, this study can be aimed to initiate treatment adjunct to IMRT to avoid or further reduce the 11\% (WRS), 15\% (WSS) drop within the first 3 weeks of IMRT. Research papers show that this can be achieved by including the use of radioprotectors and sialogogue-related radioprotectors which enables increased saliva production accompanied with radiation protection.

Drugs like amifostine when added to IMRT provided additional protection of salivary gland function and also added submandibular/sublingual gland sparing resulting in 
greater salivary flow rates. ${ }^{10}$ Also, pretreatment with phenylephrine, isoproterenol and methacholine resulted in less radiation damage to parotid gland function. ${ }^{11}$ Hence, intervention of IMRT with such treatment modalities, like radioprotectors and sialogogue-related radioprotectors would surely lead to improved health and better quality of life for patients with head and neck cancers.

\section{ACKNOWLEDGMENTS}

We are indebted to Dr Nagraj Huilgol and Dr Deepak Patkar for their support and encouragement throughout the study. The authors thank the staff from IMRT department, Dr Bhalabhai Nanavati Hospital for their technical assistance.

\section{REFERENCES}

1. Teh Bin S, Woo Shiao Y, Butler E Brian. Intensity modulated radiation therapy (IMRT): A new promising technology in radiation oncology. The Oncologist, December 1999;4(6): 433-42.

2. Williams DW, Lewis MA. Isolation and identification of Candida from the oral cavity. Oral Dis 2000;6;3-11.

3. Garg A, Malo M. Manifestations and treatment of xerostomia and associated oral effects secondary to head and neck radiation therapy. J Am Dent Assoc 1997;128:1128-33.

4. Holmes S. Xerstomia: Aetiology and management in cancer patients. Support Care Cancer 1998;6:348-55.

5. Eisbruch A. Intensity-modulated radiation therapy (IMRT): A clinical perspective. Introduction. Semin Radiat Oncol 2002;12:197-98.

6. Kohler PF, Winter ME. A quantitative test for xerostomia. The Saxon test, an oral equivalent of the Schirmer test. Arthritis Rheum 1985;28:1128-32.

7. Eisbruch A, Ten Haken RK, Kim HM, Marsh LH, Ship JA. Dose, volume and function relationships in parotid salivary glands following conformal and intensity-modulated irradiation of head and neck cancer. Int J Radiat Oncol Biol Phys 1999;45:577-87.

8. Lee Seok Ho, kim Tae Hyun, kim Joo Young, Park Sung Yong, Pyo Hong Ryull, Shin Kyung Hwan, et al. Evaluation of parotid gland function following intensity-modulated radiotherapy for head and neck cancer. Cancer Res Treat 2006;38(2):84-91.

9. Nutting CM. Intensity-modulated radiation therapy (IMRT): The most important advance in radiotherapy since the linear accelerator. The British Journal of Radiology 2003;76:673.

10. Koukourakis MI, Kyrias G, Kakolyris S, Kouroussis C, Frangiadaki C, Giatromanolaki A, et al. Subcutaneous administration of amifostine during fractionated radiotherapy: A randomized phase II study. J Clin Oncol 2000 June; 18(11):2226-33.

11. Coppes RP, Zeilstra LJ, Vissink A, Konings AW. Sialogoguerelated radioprotection of salivary gland function: The degranulation concept revisited. Radiat Res Sep 1997;148(3): 240-47.

\section{ABOUT THE AUTHORS}

\section{Sukhjinder Kaur Khosa (Corresponding Author)}

Postgraduate Student, Department of Oral Medicine and Radiology Dr DY Patil Dental College and Hospital, Navi Mumbai, Maharashtra India, e-mail: sukhjinderkaurkhosa@gmail.com

\section{Sonal Vahanwala}

Professor, Department of Oral Medicine and Radiology, Dr DY Patil Dental College and Hospital, Navi Mumbai, Maharashtra, India

\section{Sandeep S Pagare}

Professor and Head, Department of Oral Medicine and Radiology Dr DY Patil Dental College and Hospital, Navi Mumbai, Maharashtra India 